international entrepreneur, and the wide appeal of this particular book.

Djerassi will long be remembered for an article he wrote in Science in 1970 (Science 169, 941-951) entitled "Birth control after 1984 ", and his book is an extension and development of the ideas put forward in that article. The need to redouble our efforts in contraceptive research and development is self-evident at a time when the world's population is still continuing to increase by about 150,000 people a day; this single fact still continues to pose the greatest threat to the peaceful co-existence of mankind in the future.

Our principal goal must be to develop new approaches to contraception capable of deployment on a massive scale to meet the needs of the developing world; of relatively minor importance is the improvement of methods that we already have in the West, so as to maximize their efficacy and minimize their attendant health hazards. But unfortunately it is our obsession with these latter objectives in developed countries that has seriously impeded research into new contraceptives. Much of this research must inevitably be carried out in the West, because it is only in the developed countries that we have all the necessary facilities, funds, and trained minds, together with the industrial knowhow to exploit the discoveries. Herein lies the dilemma. In the first place, the declining rate of population growth in Western nations has allayed public and political concern for the problem, so that governmental support for research has now switched to more immediate problems such as alternative energy sources. This change in emphasis has coincided with the development of a plethora of governmental regulations about drug safety, and the establishment of a bureaucracy to enforce them. The statutory requirements for long-term animal toxicity testing before a drug can be marketed means that it may take from 10 to 17 years between the discovery of a compound, and its approval for clinical use by the regulatory agencies. Thus it is hardly surprising that new product development in the contraceptive field has become one of the least attractive areas of research for the pharmaceutical industry; but without the active involvement of industry, our hopes of any significant new contraceptive developments are faint indeed.

In our national drug regulatory agencies we have created organizations who have absolute power, but no sense of responsibility to see that a compound that is desperately needed is ultimately marketed; witness the status of the injectable contraceptive Provera. Surely we need to establish some mechanism whereby the pharmaceutical industry and the regulatory agencies could have a common cause once it has been agreed that there is a need to develop drugs to meet a particular demand. Under the present system, the regulatory agency acts as State prosecutor, and private industry is the defendant. The case only comes to trial after years of time and effort and, as Djerassi points out, the pharmaceutical company does not have a friend in court. Surely there would be much to be gained by exchanging the trauma of a final examination for some type of continous assessment?

Although agreeing with the need for governmental regulations about drug development and safety testing, Djerassi highlights the bureaucratic stupidity of some of the consequences. For example, the US Food and Drug Administration's requirements for condoms have meant that America produces the thickest condoms of any country in the world; if standards were relaxed to permit a $1 \%$ increase in the incidence of pin-holes, condom thickness could be reduced by half, and the increased risk of pregnancy resulting from this would only be one conception per 2.5-5 million acts of coitus. The instructions that now must accompany each packet of oral contraceptives are almost unintelligible even to the expert, and Djerassi contrasts this to the simple and effective wording that is used in China. Indeed, the chapter devoted to birth control in China is one of the most fascinating and challenging in the whole book.

Djerassi inevitably paints a rather gloomy picture about our ability to develop those new approaches to contraception which we so desperately need. But he may be unduly pessimistic, as he has based his strategies for the future on a logical planned approach of contraceptive research and development, and has ignored the major role that accident and chance can take in such affairs. For example, we can derive some comfort from the fact that in reviewing probable future developments in the field, Djerassi does not even mention what to many seems to be the most exciting hope for the future, the use of analogues of gonatrophin releasing hormone. It has recently been shown that daily administration of microgram amounts of one of these peptides can effectively inhibit ovulation for long periods of time in monkeys and in women. Here we have an example of a serendipitous discovery; these readily synthesized, non-toxic, nonsteroidal compounds were developed by the pharmaceutical industry for the treatment of some forms of infertility, but paradoxically they can also be used as contraceptives. As they have already passed many of the drug regulatory agencies' hurdles, and are on the market in some countries, they could be available for widespread clinical use within a few years from now.

So the future is full of hope and promise, provided that the West can increase its funding for contraceptive research, and remove the existing bureaucratic impediments to commercial development. But there are many obstacles to be overcome if we are to develop a rational approach to contraceptive research and development, and the world must be indebted to Carl Djerassi for pointing out some of the illogical constraints we have imposed upon ourselves. There can be no doubt as to the truth of his general conclusion that it is the politics of contraception, rather than the science, that now plays the dominant role in shaping the future.

R.V. Short is Director of the Medical Research Council Unit of Reproductive Biology, Edinburgh, UK.

\section{The micro future?}

The Mighty Micro. By C. Evans. Pp. 255. (Gollancz: London, 1979.) £5.50.

OVER the past 20 years, many voices have noisily if somewhat prematurely hailed the advent of the computer revolution. It has had no more enthusiastic advocate than the late Christopher Evans, whose premature death occurred after The Mighty Micro had been published. It has for long been customary to place the revolution about two decades after the date at which the prediction is made, and Dr Evans adheres to this convention. By AD 2000, we will have, according to him, universal electronic mail, greatly improved Prestel sets on our wrists, and permanently worn silicon chips to monitor our health and automatically inject corrective drugs as needed. Money will have been abolished

\section{Stuart Sutherland}

since all financial transactions will be computerized, and computers will administer psychotherapy and justice as well as taking over the function of the teacher: bookshops and libraries will no longer exist, since it will be possible to call up anything ever published on your drawing-room VDU.

The Mighty Micro is written for the general public, not for the specialist. It is lively and entertaining, but makes no attempt to describe how a silicon chip works nor does it provide any insights into the intricacies of computer software. It contains some good anecdotes about the forerunners and pioneers of computing Babbage, Hollerith, Zuse and Schreyer (who developed special-purpose computers in Germany in the Second World War), Aitken, Turing and Von Neumann. The pioneers saw a visionary 
future for computing, but without the invention of the silicon chip their visions could never have been realized, and that invention, as Dr Evans points out, could never have been foreseen. It transformed the cost, speed and reliability of computers, and made it practical to multiply the components almost without limit.

Most of The Mighty Micro is devoted to the future, and is speculative rather than closely argued. Dr Evans relies heavily on analogies, many of them striking. To give the reader an idea of what the exponential growth in computers portends, he points out that a piece of paper folded on itself 50 times would stretch beyond the orbit of Mars, a result that few would guess without calculation. The analogy may be better than he realizes: just as there are practical limits to such exponential growth in the thickness of a piece of paper, so there are invariably factors that set limits to the continuing exponential growth of a new technology.

Perhaps the most obvious such factor is the provision of the sort of software Dr Evans envisages. $\mathrm{He}$ is surely being unduly sanguine when he writes "There is no suggestion that before substantial improvement [in machine intelligence] can take place, any new principles must be invoked or new discoveries made"'. It is true that advances in artificial intelligence have over the last ten years thrown some light on how the human brain is likely to execute certain tasks, but the mirage of actually using intelligent programs to do something useful constantly recedes from us and there is still only a handful of applications. One reason is that very few general principles have been discovered, and it is necessary to work out $a b$ initio the structure of each new intelligent task before attempting to program a computer to execute it. Hence, computers have so far proved to be an effective substitute for the human brain only in tasks, such as mass spectrometry and chess, the structure of which has been made explicit and which necessitate a search through a vast number of alternative possibilities. Where, as in economic decision taking, we have little understanding of the task, computers cannot carry it out unaided, and are probably more of a hindrance than a help to our own thinking if used as a tool, since the spurious authority of computer forecasts may make us forget the fallibility of the assumptions on which the forecasts are based. As for Dr Evans' claim that we will shortly be able to design a machine that is more intelligent than ourselves and which can in turn design machines more intelligent than itself, we have at the moment no inkling of how to set about such a problem; nor is there any evidence to suggest that it would ever be possible. There remains, then, an astounding gap between the prognostications of some practitioners of $\mathrm{AI}$ and the performance of existing programs, and there is no sign of the impending discovery of a software equivalent of the silicon chip that will open the way to dramatic advances in the subject.

Although Dr Evans may have compressed the time scale, computers will inevitably change our living conditions; but his enthusiasm for the prospect will not be shared by everyone. He appears to think that the extra leisure time left when computers are performing most of both the important and the menial jobs can be filled by playing games against them: but people like to feel they are doing something useful and a life devoted to such games would be a hell of boredom. The Greeks, provided with leisure by slave labour, occupied themselves with making war on their neighbours, parochial politics and speculations about the nature of the Universe. We can no longer fill our time by making war, and if computers were ever able to take political decisions more sensibly than ourselves and to undertake advanced scientific work, it would come to seem pointless for us to engage in these activities. It is perhaps fortunate that in the lifetime of anyone now living we are unlikely to design our own intellectual successors, and hence render ourselves redundant.

Stuart Sutherland is Director of the Centre for Research on Perception and Cognition, University of Sussex, Brighton, UK.

\section{SCIENTIFIC BOOKSHOP}

H. K. LEWIS can supply works in all branches of Pure and Applied Science. Catalogues on request. Please state interests.

\section{SCIENTIFIC LENDING LIBRARY}

Annual Subscription from $\mathbf{8 7 . 5 0}$. (Available in U.K. only)

Reduced rates for multiple subscriptions.

Prospectus post tree on request.

Quarterly List of New Books and new editions added to the Library sent post free to subscribers regularly.

$$
\begin{gathered}
\text { H. K. LEWIS } \\
\text { \& CO. Ltd. } \\
\text { 136 GOWER STREET, } \\
\text { LONDON, WC1E GBS }
\end{gathered}
$$

